\title{
Publicaciones periódicas e imprentas de La Habana entre 1824 y 1845 en los archivos cubanos y españoles
}

\author{
José María Aguilera Manzano
}

Escuela de Estudios Hispano-Americanos, CSIC

El objetivo de esta investigación ha sido la elaboración de una "ficha biográfica" de todas las publicaciones periódicas e imprentas de La Habana entre 1824 y 1845. En ellas hemos descrito los rasgos más significativos de cada obra, con el objetivo de poner de manifiesto cómo se editaron periódicos que respondían a ideologías muy diversas. Junto a ello, de forma paralela, hemos intentado averiguar qué números de estos textos están disponibles actualmente en las colecciones existentes en Cuba y España. Esto nos ha permitido "reconstruir" obras que sólo se conservan de forma parcial a uno y otro lado del Atlántico.

PALABRAS ClaVE: prensa, imprenta, Cuba, literatura, liberalismo.

This paper provides a "biographical record" of all journals and printing press of Havana between 1824 and 1845. Each description highlights the more salient features of the journal and printing press. The objective of this exercise was to show the different texts with different underlying ideologies that were produced at this time in Havana. To add depth to this work, some magazines and newspapers of that period have been 'reconstructed' in a virtual way, by putting together those numbers available in Cuba with those that have survived only in Spanish collections.

KEYwORDS: journals, printing press, Cuba, literature, liberalism.

\section{Introducción}

El objetivo del trabajo que aquí presentamos es facilitar la investigación al estudioso de la historia de la isla Cuba del período comprendido entre 1824 y 1845 , una etapa clave en el proceso de construcción de su identidad nacional. El origen de todos estos cambios debemos buscarlo a finales del siglo XVIII y principios del XIX, cuando se produjo el tránsito del Antiguo Régimen al sistema liberal en el Imperio español. ${ }^{1}$ La Corona,

1 Fontana, Josep: La crisis del Antiguo Régimen 1808-1833, Crítica, Barcelona, 1979; Artola, Miguel: Antiguo Régimen y Revolución liberal, Ariel Historia, Barcelona, 1979. 
arrastrada por las circunstancias, se vio obligada a reconvertir el territorio peninsular en un estado nacional al estilo del francés. Esto hizo que los distintos grupos liberales que ostentaron el gobierno se tuvieran que plantear qué hacer con todos los territorios de América. Poco a poco se fue abriendo paso la idea de trasformar y dar una categoría inferior (sobre el papel porque en la práctica ya era así) a estos lugares. ${ }^{2}$ Frente a ellos aparecieron grupos de poder local en toda América y, específicamente, también en la isla de Cuba que apoyaron la construcción de proyectos nacionales distintos al que se les trataba de imponer desde la metrópoli. ${ }^{3}$ En el proceso de construcción de todas esas nuevas entidades nacionales, desde la península, América y La Habana se utilizó la literatura. La censura impuesta a las publicaciones políticas hizo que estas ideas se tuvieran que revestir a través de la literatura para poder darlas a la luz. Todo ello provocó que la prensa y las imprentas adquirieran un protagonismo hasta entonces desconocido en el mundo hispano. ${ }^{4}$ Por este motivo, las obras periódicas y literarias cubanas de esta época contienen una gran cantidad de información política sin explotar por el historiador y el crítico literario. Consecuentemente, el examen de estos periódicos arrojará una visión inusualmente rica de la historia y cultura de la capital y de la isla. ${ }^{5}$ Sin embargo, paradójicamente, los estudiosos de la historia de la mayor de las Antillas han ignorado hasta muy recientemente estas fuentes.

\section{Lugares de conservación de los periódicos}

El primer problema con el que se encuentra el investigador al tratar de profundizar en el conocimiento de la prensa cubana del siglo XIX es su dispersión y la dificultad para acceder a las series completas de la que se con-

2 Fradera, Josep María: Colonias para después de un imperio, Ediciones Bellaterra, Barcelona, 2005.

3 Chevalier, François: América Latina. De la independencia a nuestros días, Fondo de Cultura Económica, México, 1999; Moreno Fraginals, Manuel: El ingenio. Complejo económico social cubano del azúcar, Crítica, Barcelona, 2001.

4 Jacksic, Iván (ed.): The Political Power of the Word: Press and Oratory in NineteenthCentury Latin America, Institute of Latin American Studies, Londres, 2002; Anderson, Benedict: Comunidades imaginadas. Reflexiones sobre el origen y la difusión del nacionalismo, Fondo de Cultura Económica, México, 1993.

5 Jensen, Larry R.: Children of the colonial despotism. Press, politics and culture in Cuba, 1790-1840, University Presses of Florida, Tampa, 1988; Schulman, Ivan A., y Miles, Erica: "A Guide to the Location of nineteenth-century Cuban Magazines", en Latin American Research Review, volumen XII, n. ${ }^{\circ} 2$, 1977, págs. 69-102. 
serva. La guía que a continuación ponemos a disposición del estudioso se ha elaborado en base a las obras encontradas en la Biblioteca Nacional José Martí y en el Instituto de Literatura y Lingüística, ambos centros en La Habana, la Hemeroteca Municipal de Madrid y la Biblioteca Nacional, en Madrid, y en el Archivo General de Indias, en Sevilla.

Sin duda alguna, la institución que guarda las colecciones más completas de prensa periódica cubana es la Biblioteca Nacional José Martí, especialmente la Sala Cubana. El origen de esta sección hay que buscarlo en 1962, cuando se inició la organización de las publicaciones periódicas y documentos del siglo XIX. Con ello se perseguían tres fines: la mejor conservación de los textos de la centuria decimonónica, la más rápida incorporación de las nuevas adquisiciones, y facilitar el servicio al público, además de ahondar en la construcción de la "historia patria cubana". Algún tiempo después, Teresa Batista Villareal, Josefina García Carranza y Miguelina Ponte realizaron una guía para el público de los fondos de prensa existentes en esta sala, que titularon Catálogo de publicaciones periódicas cubanas de los siglos XVIII y XIX. ${ }^{6}$ No obstante, esta obra tiene un defecto y es que, en su elaboración, se basaron en las clasificaciones previas hechas por la Biblioteca; sólo consultaron los originales disponibles cuando les surgía alguna duda, y no de forma sistemática. Actualmente, el Ministerio de Cultura de Cuba, del que depende la Biblioteca, está financiando un ambicioso proyecto que pretende llevar a cabo la catalogación de las obras periódicas que existen en todas las sedes de la Biblioteca Nacional en las distintas provincias de la isla.

El Instituto de Literatura y Lingüística, donde se encuentran los fondos de la antigua biblioteca de la Sociedad Económica de La Habana, es la "gran joya sin explorar". En los catálogos disponibles al público (que sólo recogen una parte de toda la documentación que existe en sus fondos) aparecen números de periódicos de la época que no existen en otros lugares, ni siquiera en la Biblioteca Nacional. Hay que tener en cuenta que la Sociedad subvencionó muchas de estas obras mediante su suscripción a un determinado número de ejemplares. Esto hizo que llegaran todos los números de estas publicaciones de forma sistemática a su biblioteca y, por tanto, deben estar allí, aunque los catálogos existentes no lo muestren. En 1984 publicaron el Diccionario de la Literatura Cubana, la mejor obra elaborada hasta la fecha sobre la historia de los periódicos cubanos y la biografía de los

6 VV.AA.: Catálogo de publicaciones periódicas cubanas de los siglos XVIII y XIX, Biblioteca Nacional José Martí, La Habana, 1965. 
principales autores de la mayor de las Antillas. Para su realización usaron sólo el material que poseía la biblioteca. ${ }^{7}$

Finalmente, debemos recordar que la isla de Cuba era una parte del Imperio español, por lo que muchos de esos números de periódicos llegaron también a la península. En el Archivo General de Indias se ha creado una sección de prensa compuesta por todos los ejemplares que se han ido hallando al catalogar los documentos. Esta colección está formada por ejemplares sueltos de las publicaciones periódicas "oficiales", como es lógico, pues allí se encuentran los números que el capitán general y el superintendente de hacienda mandaban al gobierno central para comunicarle las noticias publicadas en el Diario de La Habana, el Noticioso y Lucero de La Habana, los Anales de ciencia, agricultura, comercio y artes y las Memorias de la Sociedad Económica de Amigos del País de La Habana. La Hemeroteca Municipal de Madrid y la Biblioteca Nacional de la misma ciudad también conservan obras periódicas habaneras. En estas dos últimas instituciones las publicaciones que se guardan tienen un carácter más literario y no tan oficial, ya que son parte de donaciones de correspondencia privada entre intelectuales habaneros y peninsulares y entre los propios habaneros residentes en Madrid en el siglo XIX.

\section{Bibliografía sobre la prensa habanera}

Debido a lo explicado más arriba, la bibliografía existente sobre la prensa y la imprenta en Cuba es muy escasa; además, los autores que escribieron sobre esta cuestión tuvieron siempre la intención de afianzar la historia nacional cubana o española, por lo que basaron todas sus hipótesis en la supuesta división entre criollos y peninsulares. Con este objetivo, la Sociedad Económica de Amigos del País de La Habana impulsó, en el siglo XIX, la elaboración de varios estudios sobre la historia de esta ciudad y la isla en los que se mencionan y se aportan datos de algunas publicaciones periódicas e imprentas. Algunos ejemplos de este tipo de obras son la Historia de la isla de Cuba, de Pedro José Guiteras, ${ }^{8}$ los dos textos escritos por José María de la Torre: Compendio de geografía física, política, esta-

7 VV.AA.: Diccionario de la Literatura cubana, volumen I y II, Instituto de Literatura y Lingüística, La Habana, 1984.

8 Guiteras, Pedro José: Historia de la isla de Cuba, volumen I y II, Imprenta de Jorge R. Lockwood, Nueva York, 1865. 
dística y comparada de la isla de Cuba y Elementos de historia universal y particular de España, isla de Cuba y Puerto Rico, ${ }^{9}$ el de Jacobo de la Pezuela, Historia de la isla de Cuba ${ }^{10}$ y el de Mariano Torrente, Bosquejo económico político de la isla de Cuba.${ }^{11}$ Pero, sin duda alguna, el trabajo de más valía del siglo XIX en relación al asunto que aquí nos incumbe es el de Antonio Bachiller y Morales, Historia de las letras y la instrucción pública en la isla de Cuba, compuesta por tres volúmenes. El segundo tomo lo dedicó a estudiar el origen de la imprenta y la prensa en La Habana y la isla. En él hace un inventario de todos los periódicos publicados allí desde la fundación de la imprenta hasta 1840, incluyendo algunas características de los mismos, y también da una lista de las obras impresas en los talleres cubanos durante este período. ${ }^{12}$

No obstante, fue en el siglo XX, después de la independencia de la isla, cuando desde algunas instituciones de la recién constituida república de Cuba, fundamentalmente la Biblioteca Nacional José Martí, la Sociedad Económica de La Habana y el Archivo Nacional de Cuba, se intentaron hacer varios estudios y catálogos de las colecciones de prensa desde que apareció la imprenta en La Habana hasta bien avanzado el siglo XIX. Este proyecto formaba parte de otro más amplio, la escritura de la historia de $\mathrm{La}$ Habana y la isla en clave de estado-nación. En este contexto se enmarcan las obras de Carlos Trilles, sobre bibliografía, y la de José Toribio Medina, sobre el origen de la imprenta en la isla de Cuba. ${ }^{13}$ A partir de 1916 Joaquín de Llaverías publicó en el Boletín del Archivo Nacional una serie de repro-

9 Torre, José María de la: Compendio de geografía física, política, estadística y comparada de la isla de Cuba, Imprenta de Soler, La Habana, 1854; Torre, José María de la: Elementos de historia universal y particular de España, isla de Cuba y Puerto Rico, volumen I y II, Imprenta de Soler, La Habana, 1847.

10 Pezuela, Jacobo de la: Historia de la isla de Cuba, volumen I al IV, Madrid, 1868; Pezuela, Jacobo de la: Ensayo histórico de la isla de Cuba, Imprenta española de R. Rafael, Nueva York, 1842.

11 Torrente, Mariano: Bosquejo económico político de la isla de Cuba, volumen I y II, Imprenta de Manuel Pita e Imprenta de Barcina, Madrid-La Habana, 1852-1853.

También son muy útiles para estudiar la prensa los textos de Calcagno, Francisco: Diccionario biográfico cubano, Nueva York, 1878; Maffei, Eugenio, y Rúa Figueroa, Ramón: Apuntes para una biblioteca española, volumen II, Madrid, 1872; López Prieto, Antonio: Parnaso cubano, volumen I, La Habana, 1881; Monte, Domingo del: Biblioteca cubana, La Habana, 1882; Beristan y Souza, José Mariano: Biblioteca hispanoamericana septentrional, volumen II, La Habana, 1883; Mitjans, Aurelio: Estudio sobre el movimiento científico y literario de Cuba, La Habana, 1890.

12 Bachiller y Morales, Antonio: Historia de las letras y la instrucción pública de la isla de Cuba, volumen I al III, Cultural, La Habana, 1937.

13 Medina, José Toribio: La imprenta en La Habana, Santiago de Chile, 1904; Trilles, Carlos: Ensayo de bibliografía cubana de los siglos XVII y XVIII, Matanzas, 1907; Trilles, Carlos: Bibliografía cubana del siglo XIX, volumen I al VIII, Matanzas 1911. 
ducciones facsímiles comentadas de los ejemplares de prensa que se conservaban en el Archivo Nacional de Cuba. Entre 1957 y 1959 Emeterio Santovenia, presidente del Consejo Director Permanente de los Archivos de la República de Cuba, ordenó la recopilación de todos estos artículos en una obra constituida por dos volúmenes. Desde entonces, esta institución ha llevado a cabo la publicación de varias obras sobre la historia de algunos periódicos de distintas localidades de la isla de Cuba con motivo del centenario o bicentenario de su fundación..$^{14}$

A principios del siglo XX la Biblioteca Nacional, como indicamos anteriormente, también inició la clasificación de los documentos del siglo XIX, y muchos de ellos se publicaron en la Revista de la Biblioteca Nacional José Martí. Bastantes años más tarde, después de la Revolución de 1959, se elaboró el Catálogo de publicaciones periódicas cubanas de los siglos XVIII y XIX con todos estos materiales. ${ }^{15}$ Paralelamente, Fernando Ortiz refundó la Revista Bimestre Cubana, en la Sociedad Económica, y en algunos de sus números insertó artículos sobre la historia de este centro y la primera época de la propia Revista. En el seno de esta institución, convertida luego en Instituto de Literatura y Lingüística, también se elaboró el Diccionario de la Literatura cubana.${ }^{16}$ Durante el siglo pasado asimismo vieron la luz obras que compilaban artículos publicados en la prensa del siglo XIX sobre distintas cuestiones fundamentales en la construcción de la identidad cubana, como esclavitud, música, etc...; en este sentido merece la pena destacar los trabajos de Cosculluela, José R.: "Historia de la prensa musical en Cuba", en VV.AA.: El periodismo en Cuba, Imprenta de Pérez y Sierra, La Habana, 1945; Deschamps Chapeaux, Pedro: El negro en el periodismo cubano en el siglo XIX, Ediciones R., La Habana, 1963; Figuerola-Caneda, Domingo: Diccionario cubano de seudónimos, Imprenta el Siglo XX, La Habana, 1922; Gallegos, Tesifonte: "La prensa cubana", en Gallegos, Tesifonte (ed.): Cuba por fuera, La Propaganda Literaria, La Habana, 1898; Labraña, José M.: "La prensa en Cuba", en Cuba en la mano, Ucar, La Habana, 1940; Ricardo, José G.: La Imprenta en Cuba, Editorial Letras Cubanas, La Habana, 1989.

14 Llaverías, Joaquín: Contribución a la historia de la prensa periódica, Publicaciones del Archivo Nacional, volumen I y II, La Habana, 1957.

15 VV.AA.: Catalogo de publicaciones...; un poco antes se había publicado Tro, Rodolofo: Catálogo de la exhibición de impresos de la Biblioteca Nacional, Biblioteca Nacional José Martí, La Habana, 1951 y posteriormente Eliseo, Diego: "De impresores y talleres del siglo XIX", en Revista de la Biblioteca Nacional José Martí, volumen 66, n. o 3, 1975, págs. 87-96.

16 VV.AA.: Diccionario de la Literatura cubana... 
En los últimos años se han elaborado varios trabajos fuera de Cuba sobre la prensa y la imprenta de la isla en relación a la del resto de América, como el de Jensen, Larry R.: Children of the colonial despotism. Press, politics, and culture in Cuba, 1790-1840, University Presses of Florida, Tampa, 1988; Álvarez, Jesús Timoteo y Martínez Riaza, Ascensión: Historia de la prensa en Hispanoamérica, Maphre, Madrid, 1992; Seoane, María Cruz: Historia del periodismo en España, volumen II, Alianza Universidad, Madrid, 1983 y Sánchez Baena, Juan José: El libro en Cuba. Imprentas, bibliotecas y publicaciones periódicas de los siglos XVIII y XIX, Universidad de Murcia, Murcia, 1994. A pesar del tiempo transcurrido, en todos estos estudios se mantiene una constante: usan la prensa para demostrar la escisión que se produjo entre criollos y peninsulares y, por eso, los distintos autores dividen a las publicaciones en criollas y peninsulares, lo que para la mayoría también equivale a una división entre prensa liberal y absolutista. Sin embargo, como consecuencia del estudio llevado a cabo para elaborar el catálogo, consideramos que esta escisión criollopeninsular es artificial y no se corresponde con la realidad y, por ello, planteamos redefinir el punto de partida. La prensa habanera y cubana se fue alineando en torno a varias tendencias: una liberal centralista, otra liberal autonomista y otra defensora del Antiguo Régimen, y todas ellas estuvieron compuestas por peninsulares y criollos. Se fueron constituyendo así varios modelos políticos con distinto criterio sobre el papel que debía desempeñar la isla de Cuba dentro o fuera del naciente estado liberal español. Estos proyectos no estuvieron definidos desde un principio, sino que se fueron formado y reformando a lo largo del tiempo, hasta que quedaron fijados a finales de la década de 1840.

\section{Metodología y utilidad de la guía}

El trabajo que presentamos consta de dos partes, la primera es una lista completa de las obras periódicas, o realizadas con ese fin, de La Habana entre 1824 y 1845 ; la segunda es un índice de todas las imprentas que funcionaron en dicha ciudad en ese período de tiempo. Ambas piezas forman un trabajo conjunto, ya que las imprentas fueron los talleres donde se elaboraron las publicaciones periódicas. Es decir, es un trabajo con dos tipos de entrada: por los títulos de las obras y por los nombres de las imprentas. En primer lugar, hemos confeccionado una "ficha biografía" de cada una 
de las publicaciones, a la que se accede buscando por orden alfabético el nombre del impreso. En cada una de ellas se recogen los años de publicación del periódico, es decir, el período durante el cual vio la luz, y lugar de publicación, pues, aunque casi todos se hicieron en La Habana, varios de ellos se elaboraron en Estados Unidos financiados desde La Habana para propagar su pensamiento a nivel mundial. En este apartado también se incluye el taller en el que se imprimía, el nombre de sus fundadores, redactores, editores, periodicidad y colaboradores de los mismos. Finalmente, en el capítulo de observaciones hemos introducido algunos rasgos que hemos creído significativos para clasificar ideológicamente los textos. La segunda entrada se realiza a través del nombre de las imprentas que funcionaban en La Habana, y en las que se publicaron las obras antes mencionadas. En las "fichas biográficas" de cada una de las imprentas se incluye: lugar de ubicación del taller, año de fundación, fundador, impresor, propietario, dirección, publicaciones no periódicas que se realizaron en ella y publicaciones periódicas antes del Trienio Constitucional (A), durante el Trienio Constitucional (B) y en el período de estudio, es decir, entre 1824 y 1845 (C). Al final de cada ficha también hemos insertado un apartado de observaciones.

En segundo lugar, hemos pretendido conocer la disponibilidad de todas las publicaciones del período de estudio que aparecen en el Catálogo de publicaciones periódicas cubanas de los siglos XVIII y XIX. Al contrastar este trabajo con las obras originales que se conservan en la Biblioteca Nacional José Martí, nos fuimos dando cuenta de que el número de periódicos que figuraba en el Catálogo de esta institución no se correspondía con el que realmente existía, tampoco las fechas de los mismos: el uso inconsecuente de meses, muchos años, volúmenes, tomos, entregas, etcétera... pusieron de manifiesto la necesidad de desconfiar de lo que decía el Catálogo, pero a su vez han permitido incrementar la exactitud de nuestras anotaciones y las han completado con las publicaciones que están a disposición del público en el Instituto de Literatura y Lingüística de La Habana. Por otro lado, al llevar a cabo el estudio de las obras periódicas existentes en España, esta guía también da a conocer al investigador europeo y peninsular el material de que dispone en Madrid y Sevilla. Todo ello permitirá ahorrar tiempo y dinero al estudioso en sus investigaciones.

En tercer lugar, y gracias a estos dos trabajos previos, se tendrá una visión razonada y completa que sirva de base para digitalizar las obras en el futuro, para contribuir al intercambio de las revistas entre archivos y cen- 
tros de investigación y como guía entre las instituciones y bibliotecas de Cuba y España. Con suerte, las irregularidades y las dudas de nuestro índice serán erradicadas si algún día se lleva a cabo un proceso de digitalización de las mismas. Hasta entonces confiamos en que este trabajo sea de ayuda para aquellos investigadores que deseen adentrarse en este apasionante y crucial período de la historia de La Habana, Cuba y el Imperio español.

\section{PERIÓDICOS PUBLICADOS EN LA HABANA \\ DESDE FINALES DE 1823 HASTA 1845}

\section{EL AGUINALDO HABANERO}

Años de publicación: sólo salió el número de 1837.

Lugar de publicación: Imprenta de Palmer, en La Habana.

Redactores: José Antonio Echeverría y Ramón de Palma.

Editores: José Antonio Echeverría y Ramón de Palma.

Colaboradores: Domingo del Monte, José Antonio Echeverría, Ramón de Palma, Manuel Garay, José Jacinto Milanés y José María Heredia.

Observaciones: en él publicó Domingo del Monte algunas de sus escasas poesías y artículos: "El destino de la mujer", "El poeta" y "Una habanera en París"; José Antonio Echeverría "A una nube", "Reconciliación", "Amor", "Manuel Garay"; Ramón de Palma "Unos ojos negros", "Fastidio", "Matanzas y Yumurí", "La despedida del cruzado" y su gran poema "La peña de los enamorados"; Manuel Garay publicó "María o la hija del norte", "Para mi álbum", "El coplero", "Las ninfas matanceras"; José Jacinto Milanés su poema "Cita nocturna", "La madrugá"; José María Heredia, "El océano", "A la gran pirámide de Egipto"; Juan Francisco Manzano "Treinta años", "La cocuyera", "A la ciudad de Matanzas", "La música", "Una hora de tristeza" y J. Padrines su poema sobre Matanzas titulado "Recuerdo".

Lugar de ubicación: en la Biblioteca Nacional José Martí (en adelante BNJM) está el número de 1837, el único que se llegó a publicar.

\section{$E L A ́ L B U M$}

Años de publicación: de abril de 1838 a marzo de 1839.

Lugar de publicación: primero en la Imprenta de Boloña, posteriormente, en la Oficina de Ramon Oliva y, finalmente, en la Imprenta Literaria a cargo de Patiño, todas en La Habana. 
Redactores: Luis Caso Solá y Ramón de Palma.

Editores: Luis Caso Solá y Ramón de Palma.

Colaboradores: José Zacarías González del Valle, José Jacinto Milanés, Cirilo Villaverde, Antonio Bachiller y Morales, Anselmo Suárez Romero, José Quintín Suzarte, José Antonio Echeverría y Juan Francisco Manzano.

Observaciones: José Zacarías González del Valle publicó aquí "Las muchachas del paseo", "Una Pascua en San Marcos", "La razón”, “A Celia”, "Los ojos verdes", "La hermosura y el amor", "El cólera en La Habana", "Amar y morir", "Amor y dinero", "El baile", "Belleza”, "A una niña de cuatro años"; Ramón de Palma publicó "El temporal", "El templete", "Ritos y creencias de los primeros habitantes de Cuba y Santo Domingo", "La vida", "Memorias y recuerdos de la condesa de Merlín", "La brisa"; José Jacinto Milanés publicó "El Conde Alarcos", "A Larra", "El beso", "A una coqueta", "El mendigo", "La ramera"; Cirilo Villaverde publicó "Excursión a Vuelta Abajo", "Engañar con la verdad"; Antonio Bachiller y Morales publicó "El juramento del cruzado"; Anselmo Suárez y Romero "Puente Grande", "Carlota Valdés"; José Quintín Surzarte escribió "Veros", "El amor"; José Antonio Echeverría publicó "El peregrino"; Juan Francisco Manzano "El sueño”.

Este periódico fue la continuación de La Miscelánea.

Lugar de ubicación: la BNJM posee la colección completa.

ANALES DE CIENCIA, AGRICULTURA, COMERCIO Y ARTES

ANALES DE AGRICULTURA E INDUSTRIA RURAL

Años de publicación: la primera serie se inició en julio de 1827 y terminó en junio de 1830. La segunda serie empezó en 1831.

Lugar de publicación: desde su fundación hasta 1830 en la Imprenta del Gobierno y Capitán General, pero el año 1830 se imprimió en el taller de José María Palmer, ambos en La Habana.

Fundador: Ramón de la Sagra.

Redactor y director: Ramón de la Sagra.

Periodicidad: mensual.

Observaciones: periódico científico. Su fundador, el naturalista Ramón de la Sagra, tenía la protección del intendente Claudio Martínez de Pinillos. En él se insertaron noticias estadísticas de toda especie de interés local para la historia de las mejoras agrícolas. Fue el eco de los periódicos tecnológicos de la época de Europa.

Lugar de ubicación: la BNJM posee la colección completa.

En el Archivo General de Indias (en adelante AGI) están los números de 1830: enero, febrero, mayo y junio. 


\section{EL APOLO HABANERO}

Años de publicación: se inició el 10 de enero de 1836 y no sabemos hasta cuando se estuvo publicando.

Lugar de publicación: Imprenta de Terán, extramuros, calle de Manrique, número 62, La Habana.

Directores: Francisco Montero y Pino y Lorenzo Mier y Terán.

Colaboradores: se publicaron aquí algunas de las danzas que compuso el aficionado filarmónico N. Muñoz y Zayas, también aparecieron por primera vez en este periódico varias composiciones musicales como La canción de la Rosa.

Periodicidad: semanal.

Observaciones: era un semanario de música. La parte crítica la desarrolló haciendo el juicio de obras, óperas y otras composiciones.

BIBLIOTECA DE AMENA LITERATURA

BIBLIOTECA SELECTA DE AMENA INSTRUCCIÓN

Año de publicación: 1836.

Lugar de impresión: Imprenta de Jordá, en La Habana.

Impresor: Mariano Torrente.

Observaciones: no era un periódico, sino una obra literaria por entregas. Como estaban prohibidas las licencias para que se publicaran periódicos sin la voluntad soberana, se imprimían como obras por entregas, eludiendo así la prohibición.

Lugar de ubicación: la BNJM posee la colección completa.

\section{CALENDARIO MANUAL Y GUÍA DE FORASTEROS DE LA ISLA DE CUBA}

Años de publicación: se inició en 1781 la primera Guía y siguieron apareciendo hasta después de 1850.

Lugar de impresión: Imprenta del Gobierno y Real Sociedad Económica, en La Habana.

Redactor: la primera la redactó el señor Barrera. En 1813 se hizo cargo de ella Tomás Agustín Cervantes, que estuvo a su frente hasta 1821.

Periodicidad: anual.

Observaciones: se calculaba que tirando 600 ejemplares de la Guía y 2.000 estados de los que le acompañaban los costos ascendían a 352 pesos.

Con la Guía nació la estadística local. La Guía tenía en sus primeros tiempos 170 páginas, hasta que a partir de 1820 alcanzó unas dimensiones mayores.

Lugar de ubicación: en la BNJM están todos los números desde 1824 hasta 1845, excepto el de 1835 .

En la biblioteca del Instituto Literatura y Lingüística de La Habana (en adelante ILL) están todos los números desde 1824 hasta 1845.

En la Hemeroteca Municipal de Madrid (en adelante HMM) están los número de los años 1835, 1836 y 1837. 


\section{LA CARTERA CUBANA}

Años de publicación: de 1838 a 1840.

Lugar de publicación: Imprenta Literaria a cargo de Patiño, en La Habana.

Fundador: Vicente Antonio de Castro.

Director: Vicente Antonio de Castro.

Impresores: Patiño.

Colaboradores: Fileno, José Zacarías González del Valle y José Jacinto Milanés.

Observaciones: Fileno publicó "Una mirada en la beneficencia”, "El pecado original", "La Monja", "Paseo por la ribera", "La despedida", "El hijo de la maldición", "Muerte de Gesler", "La Habana”; José Zacarías González del Valle publicó "Las dos viudas"; Cirilo Villaverde escribió "Una cruz negra", "La joven de la flecha de oro"; José Jacinto Milanés publicó "Triste amor de un guajiro", "El hijo de un rico".

Lugar de ubicación: la BNJM posee la colección completa.

\section{LA CONCORDIA CUBANA}

Año de publicación: nació hacia 1822 y sobrevivió hasta el 31 de enero de 1824.

Lugar de impresión: hasta el número 40 en la Oficina de José Boloña, calle de Obrapía, número 37, y del número 41 al 48 en la Oficina del Gobierno y Capitán General, ambas en La Habana.

Fundador: Francisco Javier Troncoso.

Director: Francisco Javier Troncoso.

Periodicidad: en 1823 era de dos veces a la semana.

Extensión: cuatro páginas.

Observaciones: la suscripción de un mes costaba un peso. Su objetivo fue contener el movimiento político liberal. La prudencia y moderación con que se redactó el papel y las ideas de gobierno que contenía debían contribuir a que se fomentasen "sentimientos de adhesión a la metrópoli" entre sus lectores. A través de este periódico se empezó a introducir el gusto por lo romántico.

Lugar de ubicación: en la BNJM está el número de 1823: 6 de febrero.

En la HMM están los números de 1823: 25, 28, 39 y 40; 1824: 41 y 42.

\section{CRÓNICA HABANERA}

Años de publicación: el permiso para su creación lo solicitaron en 1834. El período durante el que se publicó debió ser muy breve pues su fundador partió para Europa en 1835.

Fundador: Antonio Carlos Ferrer.

Redactor y dueño: Antonio Carlos Ferrer. 
DIARIO DE LA HABANA

DIARIO DEL GOBIERNO DE LA HABANA

DIARIO CONSTITUCIONAL DE LA HABANA

DIARIO DEL GOBIERNO CONSTITUCIONAL DE LA HABANA

GACETA DE LA HABANA

Años de publicación: El Diario de La Habana comenzó a publicarse en 1810. A partir de agosto de 1812 se llamó Diario del Gobierno de La Habana, hasta 1820. Diario Constitucional de La Habana fue el nombre que se le dio en 1820 y poco después se le cambió por el de Diario del Gobierno Constitucional de La Habana, que mantuvo hasta 1823. A partir de 1823 se llamó Diario del Gobierno de La Habana hasta 1825. En 1825 se tituló de nuevo Diario de La Habana, hasta 1848.

Redactores: de 1810 a 1816 Tomás Agustín Cervantes; de 1816 a 1824 José de Arazoza; de 1824 a 1831 Antonia de la Cámara, viuda de Arazoza, y desde 1831 en adelante José Toribio de Arazoza.

Impresor: José Arazoza.

Colaboradores: entre otros muchos escribieron en él Ramón Vélez Herrera, J. F. Fresneda, Tomás Romay, Ildefonso Estrada y Zenea, Ramón de Palma, Manuel Orgallez, Narciso Foxa, Rafael de Cárdenas, Miguel Teurbe Tolón, El Lugareño (seudónimo de Gaspar de Betancourt Cisneros), Gertrudis Gómez de Avellaneda, Felipe Poey, José Güell y Rente, Miguel Cárdenas y Herrera y Felicia (seudónimo de Virginia Felicia Auber).

Precio de suscripción: en 1825 era de dos pesos intramuros y dos pesos con veinte extramuros.

Suscriptores: en 1825 contaba con 836 suscriptores intramuros y 151 extramuros, es decir, 987 en total.

Ganancias por suscripción: en 1825 obtuvo 1672 pesos de los suscriptores intramuros y 339.60 de los extramuros, lo que suponía un total de 2011.60 pesos de ganancia, más 50 pesos que se obtenían por anuncios.

Observaciones: el primer periódico publicado en la isla de Cuba fue el Papel Periódico de La Habana, en 1790, fundado por el gobernador Luis de las Casas para insertar las noticias oficiales, pues no había ningún lugar donde publicarlas, que sobrevivió hasta 1805. Le continuó El Aviso que nació en 1805 y se dejó de publicar en 1808. En enero de 1810 fue continuado por el Aviso de La Habana, que duró hasta finales de ese año.

El tamaño del periódico varió a lo largo del tiempo, también cambió el número de columnas de cada página.

Por real orden de 9 de marzo de 1815 se nombró como impresor del gobierno y Sociedad Patriótica de La Habana a José Arazoza y Soler, quien tenía también a su cargo, por concesión real de 1816, la redacción del susodicho periódico. Al fallecer Arazoza en 1824 su viuda, Antonia de la Cámara, fue auto- 
rizada, por real orden de 8 de mayo de 1825 , para continuar la redacción del mismo periódico.

Hasta 1848 el Diario de La Habana fue financiado por la Sociedad Económica. Ese año cambió de nombre y resurgió, pero con carácter privado, pues la Sociedad Patriótica se separó de su redacción, reservándose solamente su propiedad. Finalmente desapareció el Diario de La Habana el 4 de junio de 1854.

Lugar de ubicación: en la BNJM están los números de 1825: enero-marzo, 1 y 18 de abril, julio y diciembre; 1826 completo; 1827: enero-septiembre, 1 al 23 y 25 al 31 de octubre y noviembre-diciembre; 1828 completo; 1829: 26 de enero; 1830: julio-diciembre; 1831: 2-31 de enero, febrero-abril, 1-10, 12-27 y 29 de mayo, 22 de junio, julio-octubre, 1-25 y 27-30 de noviembre, 1-4 y 7-31 de diciembre; 1832: febrero, 12 de marzo, abril-mayo; 1833: 12 de febrero y julio-septiembre; 1834: 16 de febrero, 18 de abril y julio-diciembre; 1835 completo; 1836: enero-junio, 1-20 y 22-31 de junio, agostonoviembre, 1-6 y 8-31 de diciembre; 1837-1839 completos; 1840: enerojunio, 1-12 y 14-31 de julio y agosto-diciembre; 1841 completo; 1842: enero-mayo, 1-27, 29 y 30 de junio, 28-29 de agosto y 7 de octubre; 1843 completo; 1844: 2-31 de enero, febrero-mayo, 1-29 de junio, 20-31 de agosto y septiembre-diciembre; 1845 completo.

En AGI están los números de 1824: 18 de marzo, 13 de abril, 16 de mayo, 17 de julio y 27 de octubre; 1825: 1 de marzo, 3 de julio, 5 de agosto y 23 de septiembre; 1826: 12 de marzo, 29 de marzo, 9 de abril, 3 de mayo y 17 de julio; 1827: $6,10,13$ y 19 de febrero, 15 y 21 de marzo, $6,9,13$ y 15 de mayo, 2 y 18 de junio, 12 de agosto, 7 y 27 de septiembre, 9 de octubre, 20 de noviembre y 20 de diciembre; $1828: 11$ de enero, 13 y 28 de febrero; 1829 : 27 de enero, 7 de febrero, 8 y 9 de septiembre y 25 de octubre; 1830: 27 de enero, 26 de abril, 7 y 26 de agosto; 1831: 1 de febrero y 20 de marzo; 1832 : 13 de enero, 3 de marzo, 22, 28 y 29 de julio, 29 de septiembre, 11 y 26 de noviembre; 1833: 2 de enero, 15 y 25 de marzo, 20 de abril, 8 de agosto, 21, 22 y 23 de diciembre; $1834: 10,13,25-28$ y 30 de enero, 30 de mayo, 1 y 30 de junio, 17, 21 y 22 de agosto; 1835: 19 de marzo, 16 de mayo, 14 de agosto, 26 de agosto y 24 de noviembre; $1836: 8$ de junio, 4 de octubre, 19 y $27-$ 31 de diciembre; 1837: 8 de mayo y 31 de julio.

\section{EL ESPAÑOL}

Años de publicación: desde 1829 hasta 1830 aproximadamente.

Lugar de publicación: Nueva Orleans.

Redactores: era un periódico pagado por el gobierno español para defender su política en Cuba.

Lugar de ubicación: el ILL posee los números de 1829: abril-agosto y diciembre; 1830: enero-agosto. 


\section{FARO INDUSTRIAL DE LA HABANA}

Años de publicación: 28 de noviembre de 1841 a 31 de agosto de 1851 .

Lugar de publicación: Imprenta de José Quintín Suzarte, en La Habana.

Directores: José García Arboleya y José Quintín Suzarte.

Redactores: Antonio Bachiller y Morales, Cirilo Villaverde, Manuel Costales Govantes, José María Cárdenas, Carlos del Castillo e Ildefonso Vivan.

Periodicidad: diaria.

Lugar de ubicación: en la BNJM están los números de 1841: 29 y 30 de noviembre, 1, 3-5, 7-21, 23, 25-27 y 30 de diciembre; 1842: 2-11, 13, 14, 16-24, 27, 28 y 30 de enero, 1-21, 24 y 26-28 de febrero, 1-3, 5-12, 14-16, 19-22, 24, $26-29$ y 31 de marzo, 1-8, 10, 12, 14, 16, 18-22 y 24-28 de abril, 1-3, 5-9, $12-15,18-20,23,24$ y $26-31$ de mayo, $1-7,9-18,20,22$ y $24-30$ de junio, $1-$ $3,5-18,20$ y $22-31$ de julio, $1,4-7,10-12,14-20$ y 22-30 de agosto, 2-11, 13 , $15,16,18-20,23-27,29$ y 30 de septiembre, 1, 2, 4-22, 25-29 y 31 de octubre, 1-14, 16-18, 21, 24-26 y 29 de noviembre, 1-7, 9-25, 27, 29 y 30 de diciembre; 1843: 1-14 y 16-31 de enero, 1, 3, 4 y 6-8 de febrero, 1-7 y 9-31 de marzo, 1-13 y 15-30 de abril, 1-6 y 8-31 de mayo, 1-16, 18, 21, 23 y $25-$ 29 de junio, 1-11, 13-21 y 24-31 de julio, 1, 3-24 y 26-30 de agosto, 1-14, $16-19,22-24$ y $26-30$ de septiembre, octubre completo, 1-18 y 20-30 de noviembre, $1-3,5-22$ y 24-26 de diciembre; $1844: 8,9,12-24$ y 26-31 de enero, 1-3 y 6-29 de febrero, 1-9 y 11-31 de mayo, 1-13, 15-20 y 22-30 de junio, 2-12, 14-16 y 18-31 de julio, 1, 2, 4-17, 19-21 y 23-31 de agosto, septiembre completo, 1-17 y 19-31 de octubre, noviembre completo, $1-14,16-25$ y $27-$ 31 de diciembre; 1845 : 1-28 y 30-31 de enero, 1-23 y 25-28 de febrero, 1-20 y 22-31 de marzo, 1-16, 18-25 y 27-30 de abril, 1-3, 5, 7-11 y 13-31 de mayo, 1-20 y 22-30 de junio, 1-24 y 26-31 de julio, 1, 3-20 y 22-30 de agosto, 1, 2, 4-14, 17-23 y 25-30 de septiembre, 2-31 de octubre, 1-11, 13, 15, 16, 18-21, 24,25 y $27-30$ de noviembre y diciembre completo.

\section{GACETA DE LA HABANA}

Año de publicación: no se sabe cuando se inició, pero en 1823 se publicaba, y sobrevivió hasta 1825.

Lugar de publicación: en la Imprenta Fraternal de los Díaz de Castro, impresores del Consulado y del Ayuntamiento, en La Habana.

Periodicidad: en 1823 era de tres veces a la semana.

Observaciones: en ella se publicaron los oficios, las resoluciones de la sala de la Real Audiencia y también poesías.

Lugar de ubicación: en la BNJM están los números de 1823: 6 de junio y 1 de agosto.

En el AGI están los números de 1823: 14 de marzo, 1 de agosto y 2 y 7 de diciembre. 


\section{GUIA DEL COMERCIO DE LA HABANA}

Años de publicación: se publicaron al menos dos, una en 1822 y otra en 1832. Lugar de publicación: Imprenta de Palmer, en La Habana.

\section{EL HABANERO}

Años de publicación: de 1824 a 1826.

Lugar de publicación: Nueva York.

Director: Félix Varela.

Redactor: Félix Varela.

Lugar de ubicación: la BNJM posee seis números de 1824 a 1826.

\section{EL IRIS}

Años de publicación: 1826 .

Lugar de publicación: Oficina de Iris, calle de San Agustín, México D.F.

Directores y escritores: Claudio Linati, Florencio Galli y José María Heredia.

Lugar de ubicación: la BNJM posee la colección completa.

\section{LUCERO DE LA HABANA}

Años de publicación: se inició el 1 de agosto de 1831 y se fusionó con el Noticioso el 15 de septiembre de 1832, dando lugar al Noticioso y Lucero de La Habana.

Redactor: José Pereira.

Periodicidad: diaria.

Observaciones: las mejoras introducidas en los diarios Lucero de la Habana y Noticioso Comercial motivaron una competencia peligrosa entre los dos periódicos que hubiera acabado con ambos si no se hubieran unido en el Noticioso y Lucero de La Habana. Apareció por primera vez el 16 de septiembre de 1832. Se pretendía con ello aunar esfuerzos y dinero.

Lugar de ubicación: el ILL posee los números de 1831 completos y 1832 completos.

\section{LA MARIPOSA}

Año de publicación: apareció en 1838.

Lugar de publicación: en La Habana.

Directores: el químico peninsular Luis Casaseca y Cayetano Lanuza.

Observaciones: en esta revista se recogieron artículos sobre literatura, química, industria, medicina, moda, geografía, música, filosofía, historia, teatro y otras materias.

Lugar de ubicación: en la BNJM está el volumen I de 1838. 


\section{MEMORIAS DE LA REAL SOCIEDAD ECONOMICA DE LA HABANA}

Año de publicación: de 1793 a 1796, de 1817 a 1820, de 1823 a 1825 , de 1825 a 1834, de 1835 a 1845 , de 1846 a 1851 y continúan hasta 1949.

Lugar de publicación: Oficina de la Real Sociedad Patriótica y de Gobierno, en La Habana.

Redactor: José Agustín Caballero en 1794, que redactó la Memoria correspondiente al año 1793. La del año 1794 fue preparada por Juan Manuel O’Farrill. Durante la segunda etapa, desde 1817, fue designado redactor interino José de Arazoza, desde 1822 a 1825 Francisco X. Troncoso, y desde 1835 a 1845 Francisco de Paula Serrano y Joaquín J. García.

Colaboradores: en sus páginas aparecen trabajos de José Agustín Govantes, Juan Bernardo O’Gaban, Tomás Romay, Antonio Zambrana, José Silverio Jorrín, José O’Farrill, Andrés de Jáuregui, Antonio Robredo, Miguel de Cárdenas, José Agustín Caballero, Antonio Bachiller y Morales, José Varela Zequeira, Pedro Alejandro Auber, Tranquilino Sandalio de Noda, Román Agustín Cervantes, Ramón Zambrana, Francisco de Frías, Francisco Camilo Cuyas, José Zacarías González del Valle, José Antonio Saco, Rafael Matamoros, José Valdés Fauli, Antonio María Escobedo, Domingo del Monte, Félix Varela, Manuel Costales y Govantes, Félix Manuel Tancó, Juan Bautista Sagarra, Eusebio Valdés Domínguez, Antonio González Curquejo, Alejandro Ramírez, Francisco Javier Balmaseda, José Pablo Valiente, Andrés Poey, Carlos J. Finley, Nicolás Azcarate, Juan Nepomuceno, Pablo Boloix, Lucas Ariza, Venceslao de Villaurrutia y Amador García.

Periodicidad: al principio se intentó que fueran anuales, pero a partir de 1817 se hicieron mensualmente.

Lugar de ubicación: la BNJM posee todos los número de 1824 a 1845 . Durante algún período no se llamaron Memorias sino Actas.

En el AGI están los números de 1824: 1 de octubre; 1825: 1 de marzo; 1837 completo; 1838 completo.

\section{EL MENSAGERO SEMANAL}

Años de publicación: del 19 de agosto de 1828 al 29 de enero de 1831.

Lugar de publicación: Nueva York.

Director: Félix Varela y José Antonio Saco.

Lugar de ubicación: la BNJM posee la colección completa.

\section{THE MERCANTILE WEEKLY REPORT}

Lugar de publicación: La Habana.

Director: Santiago S. Spencer.

Observaciones: el texto estaba escrito en inglés y las páginas tres y cuatro contenían las listas de precios corrientes del mercado. 


\section{EL MERCURIO}

Lugar de publicación: Nueva York.

Lugar de ubicación: la BNJM posee el número de 28 de febrero de 1833.

\section{MISCELÁNEA}

Años de publicación: de septiembre de 1829 a abril de 1830, y de junio de 1831 a junio de 1832.

Lugar de publicación: Tlalpam, México.

Director: Juan Matute González.

Editor: José María Heredia.

\section{MISCELÁNEA CURIOSA}

Años de publicación: se inició el 1 de enero de 1824 y duró hasta el 31 de mayo de 1824.

Lugar de publicación: Imprenta de la Universidad y del Comercio de Antonio María Valdés, en La Habana.

Periodicidad: diaria.

Lugar de ubicación: la BNJM posee la colección completa.

\section{MISCELÁNEA DE LITERATURA}

Años de publicación: se empezó a publicar en 1827 y se concluyó a las ocho semanas, ese mismo año.

Lugar de publicación: Imprenta de Palmer, en La Habana.

Director: el abogado Antonio Franchi de Alfaro.

Periodicidad: semanal.

\section{MISCELÁNEA DE ÚTIL Y AGRADABLE RECREO}

Año de publicación: de agosto a septiembre de 1837.

Lugar de publicación: Imprenta de Boloña, en La Habana.

Editor: Luis Caso Solá.

Colaboradores: Cirilo Villaverde, Antonio Bachiller y Morales, Leopoldo Turla y José Quintín Suzarte.

Observaciones: no es un periódico, sino una obra literaria por entregas. Se insertaron en ella las leyendas de Villaverde, animando entonces el movimiento romántico.

Lugar de ubicación: la BNJM posee la colección completa. 


\section{LA MODA O RECREO SEMANAL DEL BELLO SEXO}

Años de publicación: se comenzó a publicar el 7 de noviembre de 1829 y se mantuvo hasta el 11 de junio de 1831.

Lugar de publicación: Imprenta de Lorenzo María Fernández de Terán, en La Habana.

Fundadores: Domingo del Monte y José J. Villarino.

Redactores: Domingo del Monte, José J. Villarino, José Antonio Cintra, José María Heredia, Blas Oses y Félix Crucet hasta el 12 de junio de 1830 y después Manuel González del Valle e Ignacio Valdés Machuca.

Colaboradores: Domingo del Monte (El Peregrino, Toribio Sánchez de Almodóvar, Flerido, S. J. B., C. N. y Dr. F. de P. S. I.), José Policarpo Valdés (Rosario y Polidoro), Juan Francisco Manzano (J. F. M.), Anacleto Bermúdez (Bermudes), Ramón de Palma (R. P.), Ignacio Valdés Machuca (Desval), Francisco Iturrondo (El cantor de las ruinas de la Alhambra), Francisco Camilo Cuyas (F. C. Yascu), Prudencio de Hecheverría y O’Gaban. También aparecieron trabajos anónimos hechos por Félix Varela, Blas Oses y José Antonio Cintra.

Observaciones: la idea del nacimiento de la revista se produjo en el entresuelo de una casa de la antigua calle de la Muralla o calle Ricla, esquina con la de La Habana, donde se celebraban las asiduas tertulias literarias del grupo de intelectuales que se reunían alrededor de Domingo del Monte. Realmente era un periódico científico, literario y de modas, que se publicaba con láminas en madera y con figurines grabados e iluminados. La Real Sociedad Patriótica se suscribió por un número de ejemplares que se repartían en las escuelas.

La separación de Domingo del Monte y sus amigos de la dirección de la revista se produjo el 12 de junio de 1830, por no estar de acuerdo en los temas a publicar y por problemas administrativos. Después de la separación de del Monte de la obra, ésta perdió interés y copió muchos artículos de publicaciones peninsulares.

Lugar de ubicación: la BNJM posee la colección completa.

La HMM posee los números de 1829: 7, 14, 21 y 28 de noviembre, 5, 12, 19 y 26 de diciembre; 1830: 2, 9, 16, 23 y 30 de enero, 6, 13, 20 y 27 de febrero, 6, 13,20 y 27 de marzo, 3, 10, 17 y 24 de abril, 1 y 15 de mayo.

\section{NOTICIOSO \\ NOTICIOSO CONSTITUCIONAL \\ NOTICIOSO MERCANTIL}

Años de publicación: se inició el 12 de marzo de 1813 y el 15 de septiembre de 1832 se fusionó con el Lucero de La Habana, formando el Noticioso y Lucero de La Habana.

Fundador: Manuel Francisco Salinero. 
Redactor: en 1832 José María Palmer.

Impresor: Pedro Nolasco Palmer.

Colaboradores: Juan Lobo, el poeta Manuel de Zequeira y el naturalista francés Pedro Alejandro Auber. También colaboraron Ruiz Palominos y Lorenzo Novo.

Observaciones: en 1814 se subtitulaba Diario del Comercio. En 1820 pasó a llamarse Noticioso Constitucional. De 1821 a 1832 se llamó Noticioso Mercantil. Estaba dedicado a asuntos mercantiles, políticos y comerciales.

Lugar de ubicación: la BNJM posee los números de 1825: 18-19 de junio; 1826: 19 de mayo y 18 de julio; $1828: 31$ de enero y 7-9 de mayo; 1829: 7 de septiembre.

El ILL posee los números de 1830: noviembre completo.

El AGI posee los números de 1828: 1 y 4 de febrero; 1829: 8 de septiembre.

NOTICIOSO Y LUCERO DE LA HABANA

EL NOTICIOSO Y LUCERO

DIARIO DE MARINA

Lugar de publicación: empezó a publicarse en Matanzas y posteriormente se trasladó a La Habana.

Año de publicación: se inició el 16 de septiembre de 1832, aunque otras fuentes dicen que en 1830, y se publicó hasta 1844, en que se convirtió en el Diario de Marina.

Lugar de publicación: durante muchos años se imprimió en la Imprenta del Comercio, en La Habana.

Redactor: de junio de 1836 a octubre de 1837 fue su único redactor Juan Justo Reyes (Baziloi).

Colaboradores: Nicolás Pardo Pimentel, Juan Antonio Soriano, José María Salas y Quiroga, Ramón Francisco Valdés, Francisco Muñoz del Monte, Tranquilino Sandalio de Noda (Aristo y El Guagiro), Antonio Bachiller y Morales, Francisco Iturrondo (Delio), Ignacio Valdés Machuca, Ramón Vélez Herrera, José Victoriano Betancourt, Francisco Foxa, Tomás Romay, Gaspar Betancourt Cisneros, Ramón de la Sagra, Anselmo Suárez, José Jacinto Milanés, José Policarpo Valdés y Gabriel de la Concepción Valdés.

Observaciones: el 7 de octubre de 1832 se redujo el tamaño del periódico por falta de papel. El 9 de octubre de 1834 se llamó Noticioso y Lucero de La Habana. Su tamaño varió mucho a lo largo del tiempo. Comenzó a darse a la luz en una imprenta venida de Estados Unidos que tiraba 1.500 ejemplares por hora.

En 1834 el Noticioso y Lucero de La Habana tuvo un suplemento mensual, el Recreo de las Damas, que duró hasta febrero de 1835. Los dibujos introdu- 
cidos en este suplemento de moda eran de M. P. Picard y lo redactó N. Villarino.

Lugar de ubicación: en la BNJM se encuentran los números de 1832: 16 de septiembre; 1833: 25 de junio y 23 de diciembre; $1834: 27$ de junio; $1835: 20$ de septiembre; 1836: 17 de abril; 1837: 9 de febrero; 1838: 9 de junio, 8 de agosto, 9 y 14 de diciembre; 1840: 8 de agosto, 25, 26, 28, 30 y 31 de octubre, 1 de noviembre, 3,29 y 30 de diciembre; 1842: 5 de diciembre; 1843: 1 de enero, 24-31 de agosto y 1 de septiembre.

El ILL posee la colección completa.

El AGI posee los números de 1833: 20, 22, 23, 25, 26 y 28 de diciembre; 1834: 26-29 de enero, $10,12-15,18,21,22$ y 25 de agosto; 1835: 20 de noviembre.

La HMM posee el número de 16 de septiembre de 1832.

\section{EL PLANTEL}

Años de publicación: se inició en septiembre de 1838 y finalizó en agosto de 1839. Lugar de publicación: Imprenta de Ramón Oliva, en La Habana.

Director: el poeta Ramón de Palma y el escritor José Antonio Echeverría. En su última etapa José María Andueza y Mariano Torrente.

Editor: Ramón Oliva.

Colaboradores: Pedro Alejandro Auber, Manuel José Carrera, José Jacinto Milanés, José Zacarías González del Valle, Rafael Matamoros Téllez, Felipe Poey, Manuel del Monte, Pedro Morilla, Ramón de Mesonero Romanos, José Antonio Echeverría, etc...

Lugar de ubicación: la BNJM posee la colección completa.

La HMM posee el número 10 de 1838.

\section{LA PRENSA}

Años de publicación: de julio de 1841 a mayo de 1870.

Lugar de publicación: Imprenta de Luis Caso Solá, en La Habana.

Directores: Luis Caso Solá y José García de Arboleda, en su primera época, y posteriormente Isidro Araujo de Lira y Pascual Riesgo.

Lugar de ubicación: la BNJM posee los números de 1841: 1, 4, 8, 15 y 18 de julio, $5,8,12,15,19,22,26$ y 29 de agosto, $2,5,9,12,16,19,23,26$ y 30 de septiembre, $3,6,8,10,13,15,17,20,22,24,27,29$ y 31 de octubre, $3,5,7,10$ y 21 de noviembre; 1842: 2 de enero, $2,4,6,9,11,13,16,18,20,23,25$ y 27 de marzo, 3, 6, 8, 10, 13, 15, 17, 20, 22, 24, 27 y 29 de abril, 1, 3, 6, 13, $15,17,20,22,24,27,29$ y 31 de junio; 1843: 1 de enero. 


\section{EL PUNTERO LITERARIO}

Años de publicación: desde el 3 de marzo de 1823 hasta el 30 de agosto de 1823 y del 2 de enero de 1830 al 1 de mayo de 1830.

Lugar de publicación: en la primera época en la Imprenta del Comercio de Antonio Valdés, y en la segunda en la Oficina de José Boloña, impresor de la Real Marina, ambas en La Habana.

Redactores: en la primera época lo redactaron varios jóvenes de la clase de Constitución del Seminario de San Carlos, y en la segunda Domingo del Monte (Toribio Sánchez de Almodóvar e Íñigo del Jagüey), Antonio Bachiller y Morales, José Antonio Cintra y Anacleto Bermúdez.

Impresor: José Boloña.

Periodicidad: en la primera época era semanal.

Colaboradores: publicaron en él romances cubanos Almodóvar y Anacleto Bermúdez, Manuel Zequeira y Francisco Arango y Parreño.

Observaciones: en la primera época contenía buenos artículos sobre política, legislación y literatura y excelentes versos de Alberto Lista y José María Heredia. Su lema era "Unión, cordura y libertad". Este periódico era uno de los mejores de la época. En su segunda época fue el introductor del Romanticismo en la isla de Cuba.

Lugar de ubicación: la BNJM posee la colección completa.

\section{RECREO LITERARIO}

Advertencia: no era un periódico, sino una obra literaria por entregas.

Años de publicación: de junio de 1837 a junio de 1838.

Lugar de publicación: Imprenta de Jordá primero y luego Imprenta Literaria, ambas en La Habana.

Redactor: Mariano Torrente.

Periodicidad: mensual.

Extensión: diez volúmenes.

Observaciones: era una colección escogida de novedades científicas, cuadros históricos, artículos de costumbres y misceláneas jocosas.

Lugar de ubicación: la BNJM posee la colección completa.

La HMM posee la colección completa.

\section{EL REDACTOR DE NUEVA YORK}

Años de publicación: no se sabe cuando se inició, pero de 1827 a marzo de 1832 se estaba publicando.

Lugar de publicación: Nueva York. 
Lugar de ubicación: la BNJM posee los números de 1829: enero-mayo, 20 y 30 de junio, julio y 10 de agosto; 1831 : junio completo, 2 y 9 de julio, 27 de agosto, 3 y 10 de septiembre y 26 de noviembre; 1832: 31 de marzo.

REGAÑÓN DE LA HABANA

NUEVO REGAÑÓN DE LA HABANA

EL REGAÑÓN, SEMANARIO DE LA HABANA

EL REGAÑÓN DE LA HABANA

Años de publicación: primera época de 1801 a 1802. La segunda época empezó en 1830 y terminó hacia febrero de 1832.

Lugar de publicación: durante el Trienio Liberal en la Imprenta de Boloña, en la segunda época en la Oficina del Gobierno y Capitán General, ambas en La Habana.

Redactor y director: en la primera época Buenaventura Pascual Ferrer. En la segunda su hijo Antonio Carlos Ferrer.

Colaboradores: en la segunda época Buenaventura Pascual Ferrer, Antonio Bachiller y Morales, Claro Veraz, Renato Nerfiro, Tío Tabares, El Avizorador de Cuba, Justo Palo, El Preguntón, Parcasio H. S. y otros.

Periodicidad: semanal.

Observaciones: en la primera etapa tuvo un carácter de crítica. En la segunda época fue más científico que literario. En primer lugar aparecía una sección llamada "Mesa Censoria", que era un artículo hecho por el redactor del periódico y que se dedicaba al análisis de la prensa de la época. En esta segunda época también aparecieron las primeras producciones literarias de Antonio Bachiller y Morales.

Lugar de ubicación: la BNJM posee los números de 1830: 9, 16, 23, 30 de noviembre y 7 de diciembre; $1831: 11,18$ y 25 de enero, febrero-junio y 5 de julio.

La HMM posee el número de 1831: 12 de julio.

\section{REPERTORIO CUBANO DE CIENCIAS, LITERATURA Y ARTES}

Años de publicación: desde 1834.

Lugar de publicación: Imprenta del Gobierno y Capitán General.

Director: Antonio Franchi Alfaro.

Lugar de ubicación: la BNJM posee la colección completa.

\section{REPERTORIO DE CONOCIMIENTOS ÚTILES}

Años de publicación: se inició en 1840 y concluyó en abril de 1841. Lugar de publicación: Imprenta de Ramón Oliva, en La Habana. 
Directores: Antonio Bachiller y Morales y el peninsular Ildefonso Vivanco.

Editor: Villarino.

Impresor: Ramón Oliva.

Colaboradores: Antonio Bachiller y Morales y Vivanco fueron los autores de la mayoría de los artículos que aparecieron en este periódico. También colaboraron en él otros autores que firmaron como Santiago de la Cruz y A. W. de Schlegel.

Lugares de suscripción: en las librerías del Gobierno y Capitanía General, calle de la Obra Pía, en la de Ramis, en la de Palmer, en la Imprenta de la calle de Mercaderes y en la Imprenta de la calle de Manrique.

Periodicidad: semanal.

Precio de suscripción: dos pesos cada cuatro números intramuros y 18 reales extramuros cada cuatro números.

Observaciones: el tema fundamental fue la agricultura, aunque también se trataron cuestiones de arte, ciencias naturales y literatura. Se publicaron artículos de medicina, moral, educación, música, etc... y también ciertas cartas del poeta José María Heredia dirigidas a su tío Ignacio José de Heredia.

Del Monte y sus compañeros fundadores de la revista se fueron de ella y ésta disminuyó su calidad pues cada vez se publicaron menos trabajos originales y más copiados de diarios peninsulares y extranjeros. El abandono de del Monte y los suyos fue por diferencias de criterio en lo tocante a los materiales que debían ocupar las paginas de la revista. Tampoco estaban de acuerdo en la forma de administrar la revista.

Lugar de ubicación: la BNJM posee la colección completa.

\section{REPERTORIO MÉDICO-HABANERO}

Años de publicación: de noviembre de 1840 a abril de 1845 .

Lugar de publicación: La Habana.

Fundador: el catedrático de anatomía Nicolás José Gutiérrez.

Directores: Nicolás José Gutiérrez y posteriormente Manuel Valdés Miranda.

Redactores: los primeros fueron Ramón Zambrana y Valdés y Luis Costales.

Observaciones: fue el primer periódico dedicado solamente a la medicina y el censor que dio el permiso para su publicación fue José Antonio de Oloñate.

Lugar de ubicación: la BNJM posee la colección completa.

\section{REVISTA GENERAL DE ECONOMÍA POLÍTICA}

Años de publicación: desde agosto de 1835 .

Director: Mariano Torrente. 


\section{REVISTA Y REPERTORIO BIMESTRE DE LA ISLA DE CUBA}

REVISTA BIMESTRE CUBANA

Años de publicación: de mayo de 1831 a mayo de 1834.

Lugar de publicación: Imprenta Fraternal de Boloña y posteriormente en el Taller del Gobierno, ambos en La Habana.

Director: hasta 1832 la Comisión Permanente de Literatura, aunque realmente su director era Mariano Cubí Soler, y de 1832 a 1834 José Antonio Saco.

Redactores: Domingo del Monte, Félix Varela, José de la Luz y Caballero, José Antonio Saco, Luis Santos Suárez y otros.

Colaboradores: Domingo del Monte, Felipe Poey, Félix Varela, Luis de Mata y Araujo, Blas Osés, Esteban Moris, Pedro Sirgado, Francisco Ruiz, José Antonio Echeverría, José de la Luz y Caballero, Anastasio Carrillo, Joaquín Santos Suárez y otros.

Observaciones: En el segundo número cambió su nombre originario y se llamó Revista Bimestre Cubana.

Lugar de ubicación: la BNJM posee la colección completa.

La BNM posee, de 1831: números 1, 2 y 4; 1832: número 5, 6 y 7.

La HMM posee, de 1832: número 5.

\section{LA SIEMPREVIVA}

Años de publicación: se inició en 1837 y no se sabe cuando se concluyó.

Lugar de publicación: Imprenta del Gobierno, en La Habana.

Fundador: José Quintín Suzarte.

Impresor: José Quintín Suzarte.

Colaboradores: Antonio Bachiller y Morales, Manuel Costales y Govantes, José Victoriano Betancourt y José Quintín Suzarte.

Extensión: tres volúmenes.

Observaciones: esta revista fue definida como una de las mejores publicaciones periódicas de la isla de Cuba. Estaba dedicada a la juventud habanera. Algunas de las obras publicadas en La Siempreviva fueron: de José Silverio Jorrín "El sunsun", "El suicida", "La Habana vista desde la loma de Guanabacoa" y "El dante"; de José Zacarías González del Valle "Una retreta de junio"; de Antonio Bachiller y Morales "Recuerdos de mi viaje a Puerto Príncipe", "El colibrî", "Pena de muerte en España", "Francia e Inglaterra", "Costumbres", "El guajiro o la consulta de un letrado", "El hombre incombustible", "El clavel"; de José Victoriano Betancourt "El Torreón de San Lázaro", "El jugador" y "El cocuyo"; de José Quintín Surzarte "Desvaríos" y "La mujer buena"; de I. Vivanco "Excursión a la Vuelta de Arriba" y 
"Sagua la Grande"; de Cirilo Villaverde "A don José Quintín Suzarte desde la Sierra del Aguacate" y la primera versión de "Cecilia Valdés"; de José Manuel de Castro "El presidiario".

Lugar de ubicación: la BNJM posee la colección completa.

\section{IMPRENTAS DE LA HABANA DESDE 1823 HASTA 1845}

IMPRENTA DE FRANCISCO JOSÉ DE PAULA

IMPRENTA DE MANUEL AZPEITIA

IMPRENTA DE BOLOÑA

Lugar de ubicación: La Habana.

Año de fundación: el 4 de junio de 1735.

Fundador: Francisco José de Paula.

Propietario: primero Francisco José de Paula, posteriormente Manuel Azpeitia y, finalmente, Esteban Boloña. Cuando este último murió, la imprenta la heredaron su esposa e hijo.

Impresor: primero lo fue Francisco José de Paula, desde 1735 hasta 1741, en que éste la vendió a Manuel Azpeitia. Este último en 1787 se la cedió a Esteban Boloña y a partir de ahí la imprenta pasó de padres a hijos dentro de la familia Boloña, hasta mediados del siglo XIX.

Dirección: cuando la imprenta la heredó José Boloña, en el Trienio Constitucional, la dirección era Calle de la Obraría, número 37; hacia 1840 puede que se trasladara a la calle Villegas, número 95, aunque quizá ésta sea la dirección de la Imprenta Eclesiástica que también regentaba José Boloña; en 1841 se trasladó a la Calle de los Oficios, número 12.

Publicaciones no periódicas: lo primero que se imprimió fue una tesis universitaria, luego una hoja orlada de dos pliegos de Juan Bautista Sollozo y Urrea, en 1736; un folleto de siete hojas que contenía la tesis de Pedro Francisco de San Martín, en 1741; El cementerio, poema compuesto por Manuel de Zequeira y Arango, 1806; Declaración hecha en cuartetos heroicos contra la francesa perfidia, con motivo de la prisión de las personas reales, dedicada por un apasionado a nuestro benigno gobernador y capitán general, sin autor, 1808; Instituciones de filosofía ecléctica para el uso de la juventud, sin autor, 1814; Obligaciones de los empleados para las factorías subalternas en lo interior de la isla, sin autor, 1817; Memorias de la clase de derecho patrio del Real y Conciliar Colegio Seminario de La Habana, sin autor, 1819; Carlos IX o la escuela de los reyes, tragedia en cinco actos, sin autor, 1823; Obsequio que dedica un vecino de esta ciudad por su feliz arribo..., sin autor, 1823; Tratado de cosmografía que siguen los discípulos del presbitero escolapio Ramón Otero..., sin autor, 1826; Ordenanza de la junta de gobierno y 
de la suprema de apelaciones de la real casa y patrimonio..., sin autor, 1828; Cantatas, de Antonio Valdés Machuca, 1829; Ejército de cañón para servir a un tiempo las baterías de estribor y babor en los bajeles..., sin autor, 1829; Constituciones de la Real y Pontificia Universidad de San Gerónimo, fundada en el Convento..., sin autor, 1833; Colección de poesías arregladas por un aficionado a las musas, sin autor, 1833; Historia de la Real Casa de Maternidad de esta ciudad..., de Evaristo Zenea, 1838; Reglamento de campanas y pompa fúnebre mandada observar en esta diócesis en el que van..., sin autor, 1840; Novena en obsequio de la pródiga y amabilísima virgen abadesa Santa Gertrudis la Magna..., de Juan Francisco González de Retana, 1840; Examen público que sobre varias materias de derecho patrio y romano según el adjunto..., de Juan Escoto y Ruiz, 1841.

Publicaciones periódicas:

El Filósofo Verdadero (A)

El Barco de Vapor (B)

La Mosca (B)

La Mujer Constitucional (B)

Primer Coscorrón (B)

El Sabelotodo o El Robespierre Habanero (B)

El Telégrafo Habanero (B)

El Tío Bartolo (B)

El Álbum (C)

Calendario Manual y Guía de Forasteros de la Isla de Cuba (C)

La Concordia Cubana (Durante el año 1823) (C)

Miscelánea Útil y Agradable Recreo (C)

El Puntero Literario (A partir de 1824) (C)

El Regañón de La Habana (C)

Observaciones: el gobernador Horcasitas concedió a Francisco José de Paula la licencia que había solicitado del cabildo para abrir una imprenta al día siguiente de su petición. Esta prisa se debía a que el establecimiento de la universidad en 1734 hacia necesaria las funciones de un impresor. De hecho, su primera obra impresa fue una tesis.

En 1792, Esteban José de Boloña obtuvo el titulo de Familiar de la Inquisición, en 1793 el de Impresor de la Real Marina, título que heredó su hijo en 1823, y en 1806 dirigía también la Imprenta Episcopal.

\section{IMPRENTA DEL CÓMPUTO ECLESIÁSTICO \\ IMPRENTA DE LA CURIA EPISCOPAL \\ $Y$ COLEGIO SEMINARIO DE SAN CARLOS}

Lugar de ubicación: La Habana.

Año de fundación: hacia 1762. 
Propietario: desde 1806 Esteban José Boloña, aunque no está demasiado claro. Impresor: desde 1806 era Esteban José Boloña y luego su hijo José Boloña.

Dirección: hacia 1840 su dirección era calle de Villegas, número 95, que coincide con la de la Imprenta de Boloña en 1840.

Publicaciones no periódicas: esta imprenta se fundó para la publicación de las obras destinadas a las órdenes religiosas y a la catedral. Publicó, además, Descripción de la magnífica real función que el Sr. Phelipe Fosdeviela y Ondeano, marques de la Torre del Orden de Santiago..., de Manuel Machado, 1772; Carta pastoral que el ilustrísimo señor D. Santiago Joseph de Hecheverría, obispo de Cuba..., de Santiago Joseph de Hecheverría, 1777.

Observaciones: en 1776 cambió su nombre por el de Imprenta de la Curia Episcopal y Colegio Seminario de San Carlos.

\section{IMPRENTA DE LA REAL MARINA}

Lugar de ubicación: La Habana.

Año de fundación: en 1785 se hizo cargo de ella Esteban José Boloña, aunque se había fundado en 1735 .

Propietario: Esteban José Boloña y luego su hijo, José Boloña.

Impresor: Matías de Mora fue impresor de este taller, pero desde 1785 fue Esteban José Boloña; cuando éste murió, su hijo José Boloña se hizo cargo de ella también.

Dirección: en 1831 era calle de Villegas, número 95.

Publicaciones no periódicas: Oda al nacimiento de la serenísima infanta doña María Isabel Luisa, por José Antonio Echeverría, 1831.

Observaciones: tenía seis prensas y cuatro operarios.

\section{IMPRENTA DE BLAS OLIVOS}

Lugar de ubicación: La Habana.

Año de fundación: hacia 1757.

Fundador: Blas Olivos.

Propietario: Blas Olivos.

Impresor: Blas Olivos hasta 1777, en que su nombre desaparece de las portadas de los impresos.

Dirección: calle Mercaderes.

Publicaciones no periódicas: Receta fácil y provechosa contra dolores y llagas provenidas de humor gálico, que se tomara en consulta de medico, de 1757; Reglamento que de orden de S.M. ha hecho el excelentísimo señor conde de Ricla..., del conde de Ricla, año 1764; D. Ambrosio Funes de Villalpando, Abarca de Bolea..., del conde de Ricla, 1764; Reglamento del servicio, 
gobierno y disciplina de la novena compañía de cadetes de La Habana..., sin autor, 1765; Defensa que por orden del Sr. D. Juan Antonio de la Colina, jefe de escuadra de la Real Armada y comandante general de La Habana..., sin autor, 1768.

Publicaciones periódicas:

Gaceta de La Habana (A)

\section{IMPRENTA DE ARAZOZA Y SOLER}

Lugar de ubicación: La Habana.

Año de fundación: en 1812 publicaba libros y otras obras, aunque no se sabe el año concreto de su fundación.

Propietario: en 1812 lo era José de Arazoza y Soler.

Impresor: en 1812 lo era José de Arazoza y Soler.

Publicaciones no periódicas: Reglamento para las milicias de infantería y caballería de la isla de Cuba..., sin autor, 1812; Discurso preliminar que a tiempo de presentar en 24 de diciembre de 1811 el proyecto de la Constitución política de la Monarquía española a las Cortes generales y extraordinarias..., sin autor, 1812; Decreto de las Cortes generales y extraordinarias, anexos a la Constitución política de la Monarquía española...., sin autor, 1813; Sucinta noticia del ramo de la cera en la isla de Cuba a fines de marzo del año 1815, sin autor, 1815; A la nave de vapor, poema de Manuel Zequeira y Arango, 1819; Relación de las demostraciones fúnebres que ha hecho de su grande sentimiento por la muerte de la reina madre, doña María Luisa de Borbón, sin autor, 1819; España libre, poema de Manuel Zequeira y Arango, 1820; Sátira contra el estudio preferente del derecho romano en nuestras aulas..., por Pudencio Hecheverría O’Gaban, 1820.

Publicaciones periódicas:

El Centinela (A)

La Perinola (A)

El Argos (B)

El Descubridor Político (B)

El Espectador económico-político (B)

La Lira de Apolo (B)

El Mosquito (B)

Observaciones: José Arazoza Soler era Impresor del Gobierno y la Real Sociedad Patriótica al menos desde 1812, porque en esa fecha se pasó a imprimir en este taller el Diario de La Habana y la Guía de Forasteros de la Isla de Cuba de la Real Sociedad Patriótica. Desde 1819 era también Impresor de Cámara y en 1820 fue nombrado Impresor del Gobierno Constitucional. 
Lugar de ubicación: La Habana.

Año de fundación: hacia 1747 y siguió funcionando durante buena parte del siglo XIX.

Impresor: primero fue Diego de la Barrera, seguido por Francisco Seguí, familiar o al menos vinculado a la familia de Blas Olivos. Desde 1812 lo era José de Arazoza y luego su viuda y descendientes.

Publicaciones no periódicas: Descripción de diferentes piezas de historia natural, las más del ramo marítimo..., de Antonio Parra, 1787; Reglamento de policía para la limpieza y desembarazo de las calles y plazas..., sin autor, 1787; Estatutos de la Sociedad Patriótica de La Habana, sin autor, 1793; Exhortación a la caridad con los pobres del Hospital de San Francisco de Paula..., Juan González, 1787; Origen y descubrimiento de la vacuna..., Pedro Hernández, 1802; Elogio del excelentísimo señor don Luis de las Casas y Arragorri, Tomás Romay, 1802; Oración fúnebre del excelentísimo señor don Luis de las Casas y Arragorri, fray Juan González, 1802; Expediente instruido por el Consulado de La Habana sobre los medios que convengan para sacar la agricultura y comercio de esta isla..., sin autor, 1808; Reglamento para las milicias de infantería y caballería de la isla de Cuba..., sin autor, 1827; Vida de Adán. Invención moral o especie de poema en prosa..., traductor D. J. M. C. B. B., 1828; El matrimonio casual: comedia original en tres actos por el licenciado..., Francisco Filomeno, 1829; Ordenanzas para el gobierno de la Casa de Beneficencia..., sin autor, 1828; Memoria sobre las causas de la vagancia en la isla de Cuba, Juan Justo Reyes, 1831; Real decreto e instrucción reglamentaria para la administración y recaudación del nuevo impuesto..., sin autor, 1831; Colección de varios artículos publicados en los periódicos de La Habana..., sin autor, 1832; Instrucción acomodada al sistema de Real Hacienda y demás circunstancias particulares de la isla de Cuba..., sin autor, 1833; Texto de lectura graduada para ejercitar el método explicativo, sin autor, 1833; Exposición histórica de algunas observaciones sobre el cólera morbo espasmódico que ha reinado en el barrio de Jesús María..., Diego Manuel Govantes, 1833; Real cedula de S. M. y señores del consejo, por la cual se manda fundar y cumplir el real decreto inscrito..., sin autor, 1835; Geometría y mecánica de las artes y oficios y bellas artes..., barón Carlos Dupin, 1837; Opúsculo que contiene el discurso que pronunció..., Alejandro Oliván, 1838; Tragedia lírica en tres actos que ha de representarse en el Teatro Principal de esta ciudad, Roberto Devereux, 1839; Tragedia lírica en dos actos. Poesía de Giovanni E. Bidera, Givanni E. Bidera, 1840. 
Publicaciones periódicas:

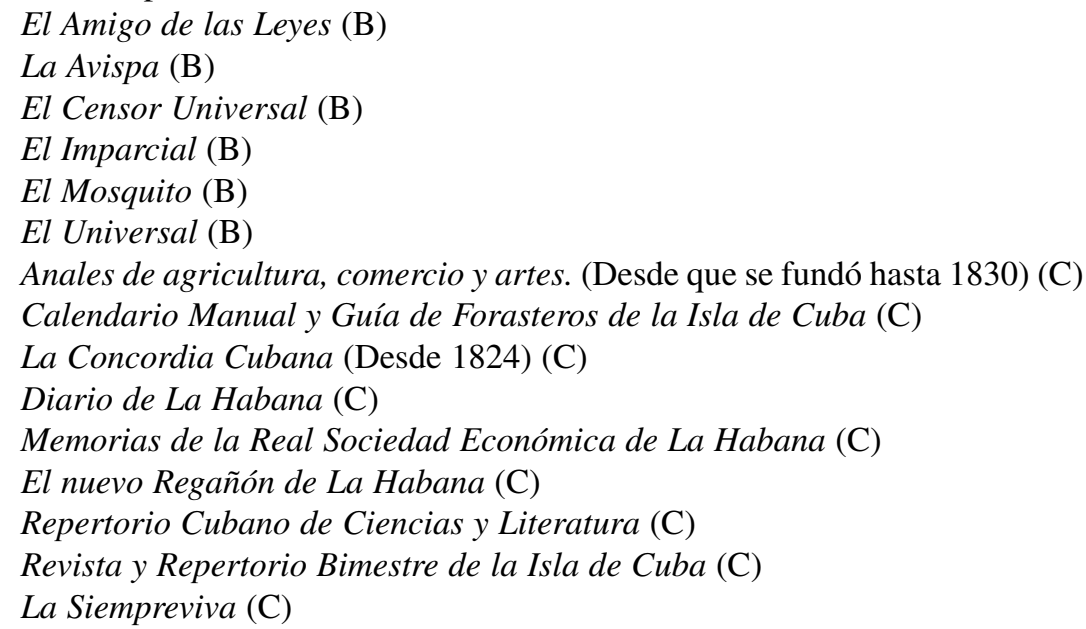

Observaciones: este taller tenía diez prensas y 59 operarios.

\section{IMPRENTA DE PEDRO NOLASCO PALMER}

Lugar de ubicación: La Habana.

Año de fundación: 1791, pero funcionó durante el siglo XIX.

Fundador: Pedro Nolasco Palmer, también conocido como Pedro Palma.

Propietario: Pedro Nolasco Palmer, hasta que a partir de 1820 figuró Pedro Nolasco Palmer e Hijo.

Impresor: Pedro Nolasco Palmer, hasta que en 1820 comenzó a aparecer el pie de imprenta como Imprenta de Pedro Nolasco Palmer e Hijo.

Dirección: calle San Ignacio, número 5.

Publicaciones no periódicas: Manifiesto que publica uno de los editores del Correo de las Damas..., Simón Bergaño y Villegas, 1811; Miscelánea filosófica escrita por el presbítero Félix Varela, Félix Varela, 1819; Apuntes filosóficos sobre la dirección del espíritu humano..., Félix Varela, 1820; Reglamento interior de la cárcel de esta ciudad....., sin autor, 1821; Observaciones sobre la constitución política de la monarquía española..., Félix Varela, 1821; La prueba o la vuelta del cruzado. Drama en un acto escrito por Ramón de Palma, Ramón de Palma, 1837.

Publicaciones periódicas:

La Aurora (A)

El Fraile (A)

El Reparón (A)

El Aguinaldo Habanero (C) 
Anales de agricultura, comercio y artes (Desde 1830 en adelante) (C)

Guía del Comercio de La Habana (C)

Miscelánea Literaria $(\mathrm{C})$

El Noticioso (C)

Observaciones: después de estar en el ejército y quedar paralítico, Palmer solicitó la fundación de una imprenta en 1777, pero ésta le fue denegada. No obstante, a través de los buenos oficios de Luis de las Casas, la Corte se la concedió y fundó su taller en 1791. Esta imprenta tenía cinco prensas y 12 operarios.

\section{IMPRENTA FRATERNAL DE LOS DÍAZ DE CASTRO}

Lugar de ubicación: La Habana.

Año de fundación: no se sabe, pero en 1821 ya funcionaba.

Propietario: Juan Díaz de Castro y Leandro Díaz de Castro.

Impresor: Juan Díaz de Castro y Leandro Díaz de Castro.

Dirección: en 1827 estaba en la plaza de San Juan de Dios; hacia 1831 se trasladó a la calle de la Obra Pía, número 112, donde permanece hasta 1839.

Publicaciones no periódicas: Pizarro y los peruanos..., 1822; Reglamento de empresa de correos marítimo..., 1827; Bando de buen gobierno, adicionado por el excelentismo señor don Francisco Dionisio Vives, Francisco Dionisio Vives, 1828; Informe presentado a la junta de gobierno del Real Consulado de la siempre fiel isla de Cuba sobre el estado de la agricultura..., Ramón de Arozarena y Pedro Bauduy, 1828; Informe que sobre el empedrado y limpieza de las calles de La Habana..., por José Pizarro y Gardín, 1831; Informe a la junta de gobierno del Real Consulado sobre el ensayo del nuevo tren de elaborar azúcar..., sin autor, 1831; La sonámbula, drama lírico en dos actos de Romaní, 1836; Exámenes generales a que han de presentarse en la tarde del día 8 de diciembre y siguientes hasta su conclusión los alumnos..., Narciso Piñeiro, 1836; Pequeña biografía clásica para la instrucción de los niños, sin autor, 1839 .

Publicaciones periódicas:

El Amigo del Pueblo (B)

Biblioteca de las Damas (B)

El Correo de las Damas (B)

El Despertador Patriótico (B)

El Lince (B)

El Navío Arranchador (B)

Observaciones: los hermanos Díaz de Castro fueron impresores del Consulado y Ayuntamiento Constitucional durante el Trienio Liberal. Este taller tenía cinco prensas y seis operarios. 
IMPRENTA DEL CONSULADO Y AYUNTAMIENTO

CONSTITUCIONAL DE LA HABANA

Lugar de ubicación: La Habana.

Año de fundación: existió durante el Trienio Constitucional, de 1820 a 1823.

Directores: Juan Díaz de Castro y Leandro Díaz de Castro.

Publicaciones periódicas:

Gaceta de La Habana (C)

Observaciones: probablemente esta imprenta no existía materialmente y sólo fue un título dado a los Díaz de Castro.

\section{IMPRENTA DE LA UNIVERSIDAD Y DEL COMERCIO}

Lugar de ubicación: La Habana.

Año de fundación: funcionó desde 1814, aunque probablemente se fundó anteriormente. En 1824 seguía existiendo y de 1832 a 1834.

Propietario: Georgina Vela y José Guerrero.

Director: Antonio María Valdés en 1824.

Impresor: Antonio María Valdés.

Dirección: calle Teniente Rey, número 81.

Publicaciones no periódicas: Tratado sobre la fiebre biliosa y otras enfermedades, Marcos Sánchez Rubio, 1814.

Publicaciones periódicas:

El Americano Libre (B)

El Indicador Constitucional (B)

El Liberal Habanero (B)

Mercurio Cívico (B)

El Puntero Literario. (Hasta fines de 1823) (B)

El Revisor Político y Literario (B)

El Sabelotodo o Robespierre Habanero (B)

Miscelánea Curiosa (C)

Noticioso y Lucero de La Habana (C)

Observaciones: contaba con tres prensas y doce operarios.

IMPRENTA DE LORENZO MARÍA DE TERÁN

Lugar de ubicación: La Habana.

Año de fundación: entre 1829 y 1831.

Propietario: Lorenzo María de Terán.

Impresor: Lorenzo María de Terán.

Dirección: calle de Manrique, número 62 extramuros. 
Publicaciones periódicas:

El Apolo Habanero (C)

La Moda o Recreo Semanal del Bello Sexo (C)

\section{IMPRENTA DE PEDRO MARTÍNEZ Y DE LA REAL JUNTA DE FARMACIA}

Lugar de ubicación: La Habana.

Año de fundación: funcionó desde 1831.

Propietario: Pedro Martínez.

Impresor: Pedro Martínez.

Publicaciones no periódicas: Petitorio formado por la Real Junta Superior Gubernativa de la Facultad de Farmacia de la isla de Cuba..., sin autor, 1834; Tarifa de los precios a que han de venderse los medicamentos simples y compuestos en las oficinas de farmacia..., sin autor, 1834.

Observaciones: contaba con dos prensas y seis operarios.

IMPRENTA DE T. JORDÁN

Lugar de ubicación: La Habana.

Año de fundación: no se sabe, pero funcionaba en 1836.

Propietario: Jordán.

Impresor: Jordán.

Dirección: calle de Mercaderes, número 89.

Publicaciones no periódicas: Revista General de la Economía Política..., por Mariano Torrente, sin año; Fisiología e higiene de los hombres dedicados a trabajos literarios o investigaciones sobre lo físico y moral..., Antonio Bachiller y Morales, 1843.

Publicaciones periódicas:

Recreo Literario $(\mathrm{C})$

Biblioteca de Amena Literatura (C)

Biblioteca Selecta de Amena Instrucción (C)

\section{IMPRENTA LITERARIA}

Lugar de ubicación: La Habana.

Año de fundación: funcionó desde 1837, cuando se imprimió en ella La Cartera Cubana, aunque no sabemos cuando se fundó.

Propietario: Domingo Patiño.

Impresor: Domingo Patiño.

Dirección: calle de Cuba, bajo el convento de San Agustín.

Publicaciones no periódicas: Explicaciones con motivo de algunos lugares de Aristóteles..., por José Zacarías González del Valle, 1839; La peña de los enamorados, por Ramón de la Palma, 1839. 
Publicaciones periódicas:

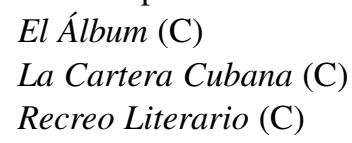

Observaciones: contaba con una prensa y seis operarios.

\section{IMPRENTA DE RAMÓN OLIVA}

Lugar de ubicación: La Habana.

Año de fundación: en 1838 y funcionó al menos hasta 1840.

Propietario: Ramón Oliva.

Impresor: Ramón Oliva.

Publicaciones no periódicas: Obsequio a las damas, editor Ramón Oliva, 1839; El campamento de los cruzados..., de Adolfo Dumas, 1840.

Publicaciones periódicas:

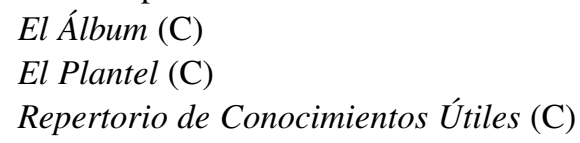

Observaciones: contaba con dos prensas y cinco operarios.

IMPRENTA DE JUAN BARANAS

Lugar de ubicación: La Habana.

Año de fundación: 1840.

Impresor y propietario: Juan Baranas.

Observaciones: contaba con dos prensas y tres operarios.

IMPRENTA DE MANUEL SOLER

Lugar de ubicación: La Habana.

Año de fundación: 1840.

Impresor y propietario: Manuel Soler.

Observaciones: contaba con dos prensas y tres operarios.

\section{IMPRENTA DE VICENTE DE TORRES}

Lugar de ubicación: La Habana.

Año de fundación: 1841.

Impresor y propietario: Vicente de Torres.

Observaciones: contaba con dos prensas y siete operarios. 


\section{IMPRENTA LITOGRÁFICA DE LA REAL SOCIEDAD ECONOMICA}

Lugar de ubicación: La Habana.

Año de fundación: 1838 y funcionó al menos hasta 1844.

Propietarios: se fundó a través de una sociedad anónima entre cuyos miembros estaban Domingo del Monte y José Luis Alfonso.

Impresor: los señores Consnier y Moreau de Jones.

Observaciones: contaba con tres prensas y cinco operarios.

\section{IMPRENTA LITOGRÁFICA DE LOS SEÑORES COSTA Y COMPAÑÍA}

Lugar de ubicación: La Habana.

Año de fundación: 1838.

Propietario: se fundó a través de una sociedad anónima.

Impresor: Costa.

Observaciones: contaba con dos prensas y cuatro operarios.

Recibido el 15 de septiembre de 2005 Aceptado el 9 de marzo de 2006 